\title{
Upregulation of TCTP is associated with cholangiocarcinoma progression and metastasis
}

\author{
NATTAPORN PHANTHAPHOL ${ }^{1,2}$, ANCHALEE TECHASEN $^{2-4}$, WATCHARIN LOILOME $^{1,2,4}$, \\ SUYANEE THONGCHOT ${ }^{1,2}$, RAYNOO THANAN ${ }^{1,2}$, SAKKARN SUNGKHAMANON ${ }^{4,5}$, \\ NARONG KHUNTIKEO ${ }^{2,4,6}$, PUANGRAT YONGVANIT ${ }^{1,4}$ and NISANA NAMWAT ${ }^{1,2,4}$ \\ ${ }^{1}$ Department of Biochemistry; ${ }^{2}$ Cholangiocarcinoma Research Institute; ${ }^{3}$ Faculty of Associated Medical Sciences; \\ ${ }^{4}$ CASCAP Program; Departments of ${ }^{5}$ Pathology and ${ }^{6}$ Surgery, Faculty of Medicine, \\ Khon Kaen University, Khon Kaen 40002, Thailand
}

Received December 10, 2015; Accepted June 21, 2017

DOI: $10.3892 / \mathrm{ol} .2017 .6985$

\begin{abstract}
In order to investigate the role of translationally-controlled tumor protein (TCTP) in cholangiocarcinoma (CCA) progression and metastasis, TCTP protein staining in paraffin-embedded sections of human CCA tissue samples was examined using immunohistochemistry, and its expression was subsequently compared with clinicopathological parameters. Small interfering RNA (siRNA) targeting TCTP (siTCTP) were transfected into CCA cell lines to evaluate its effects on cellular functions. The proliferation, tumorigenicity and migration abilities of the transfected cells were measured using sulforhodamine B, clonogenic and would healing assays, respectively. The protein levels of TCTP and its associated molecules were evaluated by western blot analysis. Of the 119 individual cases of CCA tissues analyzed, high TCTP scores were significantly correlated with overall metastasis $(\mathrm{P}=0.044)$ and a shorter survival time $(\mathrm{P}<0.001)$. Multivariate proportional hazards analysis revealed that TCTP is an independent indicator of poor prognosis in CCA (hazard ratio $=2.864 ; \mathrm{P}<0.001)$. siTCTP transfection suppressed CCA cell growth and migration abilities, compared with the control cells $(\mathrm{P}<0.01)$. The siTCTP reduced the protein levels of focal adhesion kinase (FAK), phospho-FAK, nuclear factor kappa-light-chain-enhancer of activated B cells and matrix metalloproteinase 9, suggesting potential roles of TCTP in regulating CCA progression and metastasis. In conclusion, the upregulation of TCTP is clinically significant in patients with CCA, serving roles in CCA progression, particularly in cell
\end{abstract}

Correspondence to: Dr Nisana Namwat, Department of Biochemistry, Faculty of Medicine, Khon Kaen University, 123 Mittraphap Road, Khon Kaen 40002, Thailand

E-mail:nisana@kku.ac.th

Key words: translationally-controlled tumor protein, small interfering RNA, cholangiocarcinoma, progression, metastasis, focal adhesion kinase, matrix metalloproteinase 9 survival and metastasis. Suppression of TCTP may serve as a potential target in CCA prevention and treatment.

\section{Introduction}

Cholangiocarcinoma (CCA) refers to cancer of the lining of the bile duct epithelium (1). Although it remains relatively low in most countries, the incidence of CCA is increasing worldwide (2-4). CCA is a major public health problem in the northeast of Thailand, where the incidence of the disease is the highest globally (5). Overall, 93-318/100,000 individuals/year are diagnosed (6), with 20,000 associated mortalities each year (7). CCA progression is relatively slow and patients primarily present with late stage disease, in which the cancer has spread to other organs (8). Notably, chemotherapy in combination with surgery may confine the tumor, prevent further growth of the tumor and may prolong the survival of the patients compared with surgery administered alone (9). Therefore, the underlying mechanisms, particularly changes in the molecular pathways, which drive tumor cell functions during CCA carcinogenesis and tumor progression must to be investigated in order to improve current guidelines for CCA prevention and treatment.

Translationally-controlled tumor protein (TCTP/TPT1) is a highly-conserved protein that is ubiquitously expressed in all eukaryotic organisms (10). Cellular functions of TCTP identified in diverse biological processes are associated with the promotion of cell survival by enhancing the anti-apoptotic response and suppressing pro-apoptotic activities (11). Numerous studies have established that TCTP is highly expressed in numerous types of cancer, such as colon cancer (12), prostate cancer (13) and hepatocellular carcinoma (HCC) (14). A marked association between TCTP expression levels and tumor metastasis was observed in ovarian cancer (15), colon cancer (16), and glioma (17). Although it has been well recognized that TCTP functions as an anti-apoptotic factor and contributes to malignancy (18), the molecular mechanism by which TCTP is involved in tumor metastasis remains to be elucidated. Bae et al (19) demonstrated that TCTP promotes the epithelial-mesenchymal transition (EMT) in the porcine kidney epithelial LLC-PK1 cell line via EMT regulators, including Zinc finger E-box binding homeobox 
(ZEB1) and Twist-related protein (Twist) (19). It has been also identified that TCTP induces cell invasion via matrix metalloproteinase (MMP)-9 activation in a mouse melanoma cell line and promotes cell migration via the mechanistic target of rapamycin complex 2/protein kinase $\mathrm{B} / \mathrm{glycogen}$ synthase kinase $3 \beta$ (mTORC $2 / \mathrm{Akt} / \mathrm{GSK} 3 \beta) / \beta$-catenin signaling pathway in LLC-PK1 porcine kidney epithelial cells. In addition, knockdown of TCTP inhibited the proliferation, migration and invasion activity of LoVo colon adenocarcinoma cells in vitro and in vivo (16).

TCTP is therefore considered to be a key factor in cancer development and progression. Furthermore, little is currently known about its role in CCA progression and metastasis. In the present study, the TCTP expression pattern and its clinical relevance in patients with CCA were investigated. Additionally, the effects of TCTP downregulation in CCA cell functions were also assessed using the RNA interference technique.

\section{Materials and methods}

Patients and samples. CCA tissues were collected from 119 patients admitted at Srinagarind Hospital, Khon Kaen University (Khon Kaen, Thailand) during January 2004 to December 2010. Of the 119 CCA patients investigated, $71 \%$ were male and $29 \%$ were female, resulting in a male to female ratio of 2.4. The mean age was $56.5 \pm 8.5$ years (range, 32-76 years). The protocols for the collection of tissues and for the study were approved by the Ethics Committee for Human Research, Khon Kaen University (no. HE571283), and written informed consent was provided by all patients. The 119 CCA formalin-fixed paraffin-embedded tissues stored at the specimen bank of the Liver Fluke and Cholangiocarcinoma Research Center (Faculty of Medicine, Khon Kaen University) were cut into $4 \mu \mathrm{m}$-thick sections.

Human CCA cell lines. The human KKU-M055 CCA cell line was obtained from the specimen bank of the Liver Fluke and Cholangiocarcinoma Research Center, Faculty of Medicine, Khon Kaen University. Cells were maintained in Ham's F-12 medium (Gibco; Thermo Fisher Scientific, Inc., Waltham, MA, USA) augmented with $2 \mathrm{mg} / \mathrm{ml} \mathrm{NaHCO}, 100 \mathrm{U} / \mathrm{ml}$ penicillin, $100 \mu \mathrm{g} / \mathrm{ml}$ streptomycin and $10 \%(\mathrm{v} / \mathrm{v})$ fetal bovine serum (Gibco; Thermo Fisher Scientific, Inc.) at $37^{\circ} \mathrm{C}$ with $5 \% \mathrm{CO}_{2}$.

Immunohistochemical (IHC) staining of CCA tissues. The paraffin-embedded tissue sections were analyzed by IHC staining for TCTP according to standard protocols (20). Rabbit anti-human TCTP (dilution, 1:400; cat. no. ab37506; Abcam; Cambridge, UK) was used a primary antibody for incubation with the sections at $4^{\circ} \mathrm{C}$ overnight. Subsequent to washing with PBS and Tween-20 3 times (5 min each), sections were incubated at room temperature for $1 \mathrm{~h}$ with undiluted peroxidase-conjugated EnVision anti-rabbit secondary antibody (cat. no. K4003; Dako; Agilent Technologies, Inc., Santa Clara, CA, USA), and peroxidase activity was then visualized by applying a one drop of $1 \%(\mathrm{w} / \mathrm{v})$ of 3,3'-diaminobenzidine solution for $5 \mathrm{~min}$. Hematoxylin was utilized for counterstaining. The staining frequency of proteins was semi-quantitatively scored according to the percentage of positive cells as follows: $0 \%$, negative; $1-25 \%,+1 ; 26-50 \%,+2$; and $50 \%,+3$. The intensity of protein staining was scored as follows: Weak, 1; moderate, 2; strong, 3 . The staining score was calculated by multiplying the intensities and frequencies in each case, which were then categorized into the following two groups: Low levels, $<4$; high levels, $\geq 4$ (21).

Transfection of small interfering RNA (siRNA). The siRNA targeted to human TCTP (SMARTpool ON-TARGETplus siRNA, ID L-004559-00-0005) and non-targeting pool siRNA (siRNA control, ID D-001810-10-05) was purchased from GE Healthcare Dharmacon, Inc., (Lafayette, CO, USA). CCA cells $\left(6 \times 10^{4}\right)$ were plated into a 6 -well plate and incubated for $12 \mathrm{~h}$ at $37^{\circ} \mathrm{C}$ prior to the beginning of transfection. The siRNAs and Lipofectamine RNAiMAX ${ }^{\circledR}$ reagents (Invitrogen; Thermo Fisher Scientific, Inc.) were complexed in Opti-MEM ${ }^{\circledR}$ I medium (Invitrogen; Life Technologies, Carlsbad, CA, USA), at a final concentration of $50 \mathrm{nM}$. The siRNA-treated cells were additionally maintained at $37^{\circ} \mathrm{C}$ in a $5 \% \mathrm{CO}_{2}$ incubator for $72 \mathrm{~h}$ to achieve a complete transfection. The successful suppression of TCTP expression was verified by western blot analysis. Each experiment was performed in triplicate.

Western blot analysis. Cells were washed twice (30 sec/each) with ice-cold PBS and lysed with RIPA lysis buffer containing protease $\mathrm{K}$ inhibitor cocktail $\left(0.5 \mathrm{M} \mathrm{NaF}, 0.2 \mathrm{M} \mathrm{NaVO}_{4}, 1 \mathrm{M}\right.$ Tris- $\mathrm{HCl} \mathrm{pH}$ 7.5, 0.5 M EDTA, 2.5 M NaCl, 10\% NP-40, $10 \%$ SDS, triton X-100 and deionized water) followed by homogenization for $5 \mathrm{~min}$. Following centrifugation at $14,000 \mathrm{x} g$ at $4^{\circ} \mathrm{C}$ for $10 \mathrm{~min}$, the protein concentration in the solution fractions were determined by the Pierce $\mathrm{BCA}^{\mathrm{TM}}$ Protein Assay kit (Pierce; Thermo Fisher Scientific, Inc.). Equal amounts of protein $(20 \mu \mathrm{g}$ protein/lane) were resolved on $10 \%(\mathrm{w} / \mathrm{v})$ SDS-PAGE and transferred to a polyvinylidene fluoride membrane. Following blocking the non-specific sites with $5 \%(\mathrm{w} / \mathrm{v})$ skimmed milk solution at room temperature for $1 \mathrm{~h}$, the membrane was probed with several primary antibodies, including rabbit anti-human TCTP (dilution, 1:1,000; cat. no. ab37506; Abcam, Cambridge, UK), rabbit anti-human focal adhesion kinase (FAK; dilution, 1:1,000; cat. no. ab131435; Abcam), rabbit anti-human p-FAK (dilution, 1:2,000; cat. no. ab76244; Abcam), mouse anti-human nuclear factor $\kappa$-light-chain-enhancer of activated B cells (NF- $\kappa$ B; dilution, 1:1,000; cat. no. SC-8008; Santa Cruz Biotechnology, Inc., Dallas, TX, USA), goat anti-human MMP-9 (dilution, 1:1,000; cat. no. AF911; Abcam) at room temperature for $1 \mathrm{~h}$ followed by $4^{\circ} \mathrm{C}$ for $16 \mathrm{~h}$. The expression level of $\beta$-actin was used as the loading control to normalize the amount of loading proteins by incubation with mouse-anti-human $\beta$-actin (dilution 1:10,000; cat. no. A5441; Sigma-Aldrich; Merck KGaA, Darmstadt, Germany) at room temperature for $1 \mathrm{~h}$. Following three washes, the blots were incubated with a secondary antibody conjugated with horseradish peroxidase including anti-rabbit Immunoglobulin G ( $\mathrm{IgG})$ (dilution, 1:2,000; cat. no. NA934V; GE Healthcare UK Ltd.), anti-mouse IgG (dilution, 1:2,000; cat. no. A1616; Invitrogen; Thermo Fisher Scientific, Inc.) and anti-goat IgG (dilution, 1:2,000; cat. no. R21459; Invitrogen; Thermo Fisher Scientific, Inc.) at room temperature for $1 \mathrm{~h}$. Immunodetection was performed using Amersham ECL Western Blotting Detection Reagent (GE Healthcare UK Ltd., Chalfont, UK). The images were analyzed and quantified using an ImageQuant ${ }^{\mathrm{TM}}$ Imager LAS 4000 mini 


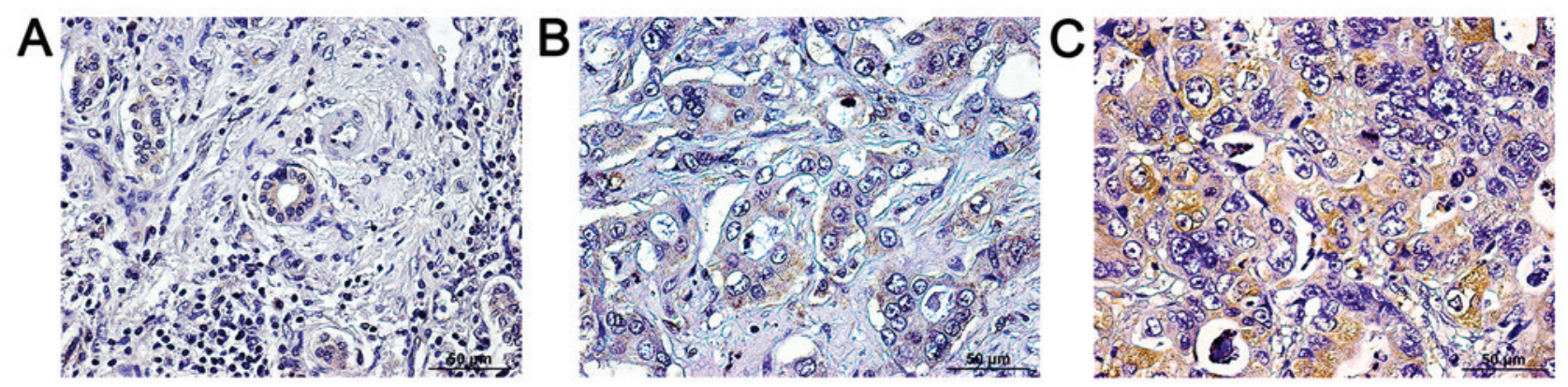

Figure 1. Immunohistochemical staining of TCTP in CCA tissues. (A) Negative staining of normal bile duct epithelial cells surrounding in the tumor area. Positive staining of the TCTP protein was detected in the cytoplasm of tumor cells. (B) Low TCTP staining was observed in CCA tissues. (C) High TCTP staining was visible in CCA tissues. Magnification, x400. TCTP, translationally controlled tumor protein; CCA, cholangiocarcinoma.

(version 1.0.0.52; GE Healthcare UK Ltd.). Each experiment was performed in triplicate.

Clonogenic assay. The ability of a single cell to form a large colony was determined using a clonogenic assay that was visible to the naked eye. Following transfection, the cells were trypsinized to make a single-cell suspension, re-seeded onto 6 -well plates $\left(2 \times 10^{2}\right.$ cells/well) and incubated at $37^{\circ} \mathrm{C}$ for 7 days to form colonies. Colonies were fixed with $4.0 \%$ paraformaldehyde at $4^{\circ} \mathrm{C}$ for $1 \mathrm{~h}$ and stained with $0.5 \%$ crystal violet at room temperature for $30 \mathrm{~min}$. Colonies were manually counted under a light microscope (magnification, x50) and analyzed using ImageJ software (version 1.4.3.67; GE Healthcare UK Ltd.). The experiment was performed in triplicate and repeated three times.

Cell viability assay. A sulforhodamine B colorimetric (SRB) assay was performed to assess cell proliferation based on the cellular protein content. The siRNA transfected cells were re-seeded in a 96-well plate $\left(2 \times 10^{2}\right.$ cells/well $)$ and allowed to grow for 24-96 h. Cell monolayers were fixed with $10 \%$ trichloroacetic acid at $4^{\circ} \mathrm{C}$ for $1 \mathrm{~h}$ and then stained with $0.4 \%$ SRB in $1 \%$ acetic acid for $30 \mathrm{~min}$ in the dark. Next, the unbound dye was removed by washing for 5 times ( $1 \mathrm{~min} / \mathrm{each})$ with $1 \%$ acetic acid. The protein-bound dye was dissolved in $200 \mu \mathrm{l}$ of $10 \mathrm{mM}$ Tris Base solution for $1 \mathrm{~h}$. The absorbance was measured at a wavelength of $540 \mathrm{~nm}$ using a Sunrise ${ }^{\mathrm{TM}}$ absorbance microplate reader (Magellan ${ }^{\mathrm{TM}}$ data analysis software version 6.6.0.1; Tecan Group Ltd., Männedorf, Switzerland). The experiment was performed in triplicate and repeated three times.

In vitro wound-healing assay. Directional cell migration ability was analyzed by a wound-healing assay. At $12 \mathrm{~h}$ post-transfection, CCA cells $\left(1 \times 10^{6}\right.$ cells/well $)$ were seeded in 24-well plates and left to adhere. The cell monolayer was scratched using sterile pipette tips to create a wound. Images were captured using a phase-contrast microscope with a digital camera (magnification, x100; Axiovert 40; Carl Zeiss AG, Oberkochen, Germany) from 0-24 h during cell migration to close the wound. The degree of cell migration in each group was compared. The size of the wound area was measured in the images using ImageJ software (version 1.4.3.67, National Institutes of Health, Bethesda, MD, USA) the migration area was calculated by using the following formula:
Migration area $=$ (area of original wound-area of wound during healing)/area of original wound. The experiment was performed in triplicate and repeated three times.

Statistical analysis. The data were analyzed using SPSS software v.19.0 (IBM Corp., Armonk, NY, USA). The correlation of TCTP with the clinicopathological parameters of the patients with CCA was analyzed by Fisher's exact test. Patient survival was computed from the date of surgical resection to mortality, and survival plots were constructed according to the Kaplan-Meier method, with a log rank test was performed to compare differences in the survival rates of patients who were subjected to surgery. A multivariate analysis was conducted using the Cox proportional hazards regression model. The significance of the data compared between siRNA-treated and control groups was analyzed using the Student's t-test. $\mathrm{P}<0.05$ was considered to indicate a statistically significant difference.

\section{Results}

Upregulation of TCTP expression correlated with poor prognosis of patients with CCA. Results of immunohistochemical staining demonstrated high expression of TCTP in $96(81 \%)$ patients and low expression of TCTP in 23 (19\%) patients. TCTP was not detected in adjacent normal bile ducts (Fig. 1A). Negative staining was identified in hepatocytes and fibroblasts observed for all cases (data not shown). Positive staining for TCTP protein was detected in the cytoplasm of tumor cells (Fig. 1B and C). Among the tumor sections of 119 patients with intrahepatic CCA investigated, 84 (71\%) cases were male and $35(29 \%)$ cases were female. The age of patients ranged from 32-76 years old (median age, 57 years). The CCA histological types were sorted as the papillary type in $20(17 \%)$ cases and the non-papillary type in $99(83 \%)$ cases. In the present study, the majority of patients were at an advanced stage, with $73(61 \%)$ cases presenting with tumor metastasis. Fisher's exact test revealed a significant positive correlation between high TCTP expression levels and overall metastasis $(\mathrm{P}=0.040)$. Age, sex, and histological grade did not demonstrate any association with TCTP protein levels (Table I). In addition, the cumulative survival of patients with CCA and low/high TCTP expression levels in CCA tissues was analyzed using the Kaplan-Meier method. As presented in Fig. 2, patients with high TCTP expression exhibited significantly shorter survival times when compared with those with low TCTP expression 
Table I. Correlation between the TCTP expression and clinicopathological data.

TCTP immunohistochemical score

\begin{tabular}{|c|c|c|c|c|}
\hline Factor & Patient no. & Low & High & P-value \\
\hline \multicolumn{5}{|l|}{ Age, years } \\
\hline$<57$ & 57 & 11 & 46 & 0.589 \\
\hline$\geq 57$ & 62 & 12 & 50 & \\
\hline \multicolumn{5}{|l|}{ Sex } \\
\hline Male & 84 & 13 & 71 & 0.084 \\
\hline Female & 35 & 10 & 25 & \\
\hline \multicolumn{5}{|l|}{ Histological type } \\
\hline Non-papillary & 99 & 17 & 82 & 0.155 \\
\hline Papillary & 20 & 6 & 14 & \\
\hline \multicolumn{5}{|c|}{ Overall metastasis } \\
\hline Negative & 46 & 13 & 33 & $0.044^{\mathrm{a}}$ \\
\hline Positive & 73 & 10 & 63 & \\
\hline
\end{tabular}

${ }^{\text {a }}<<0.05$, considered to indicate a statistically significant difference. TCTP, translationally controlled tumor protein.

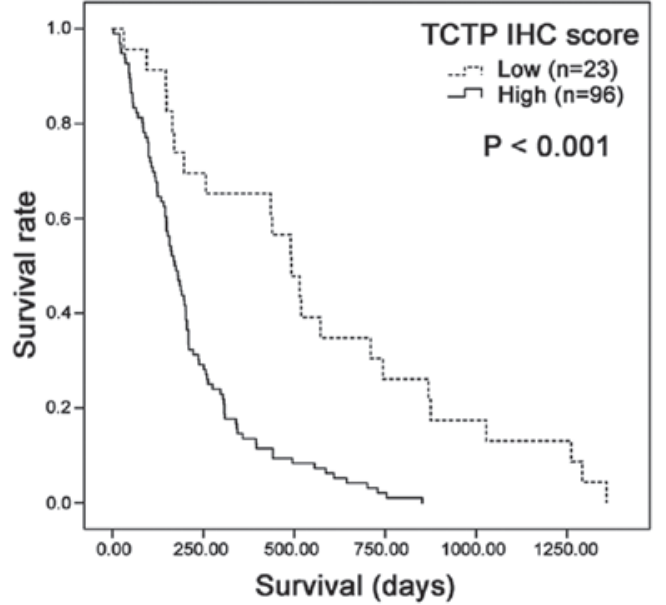

Figure 2. Kaplan-Meier estimates of the 5-year overall survival rate as a function of TCTP status demonstrated that high TCTP expression was associated with a shorter survival $(\mathrm{P}<0.001)$, as compared with low TCTP expression. TCTP, translationally controlled tumor protein.

$(\mathrm{P}<0.001)$. The prognostic value of TCTP expression and other clinicopathological parameters among patients with CCA was determined using the multivariate Cox proportional hazards regression model. The results demonstrated that high TCTP expression (hazard ratio $=2.864 ; \mathrm{P}<0.001$ ) was an independent prognostic indicator for the overall survival of patients with CCA following surgical resection (Table II).

Suppression of TCTP by siRNA reduces tumor growth in vitro. A total of $50 \mathrm{nM}$ siRNA against TCTP (siTCTP) or the negative control (siControl/NC) were transfected into KKU-M055 cells. The successful suppression of TCTP expression was verified by western blot analysis, which demonstrated a suppression rate of $>50 \%$ in KKU-M055 cells (Fig. 3A and B). Post-transfection, clonogenic and SRB assays were performed to assess tumor growth and cell viability in vitro. These results demonstrated that KKU-M055 cells transfected with siTCTP exhibited a 39\% reduction in colony numbers (Fig. 4A and B; P<0.01), and 23, 30, 40 and $36 \%$ decreases in cell viability at $24,48,72$ and 96 h, respectively (Fig. 4C), compared with the siControl transfected cells.

TCTP suppression attenuated migration ability of CCA cells. The present study examined whether TCTP silencing affected the migration ability of CCA cells. An in vitro wound-healing assay was performed with siTCTP or siControl transfected cells. The wound-healing assay was used to observe cell migration. The result demonstrated that the migration area of siTCTP transfected cells was significantly decreased in KKU-M055 cells (Fig. 5A), as compared with siControl transfected cells. Quantification was carried by measuring the wound area of migratory cells at the observation time compared with the beginning of the experiment in each group. It was identified that siTCTP reduced the number of KKU-M055 migratory cells by $24 \%$ at $12 \mathrm{~h}$ and $25 \%$ at $24 \mathrm{~h},(\mathrm{P}<0.01$; Fig. $5 \mathrm{~B})$ post-transfection. Changes in the molecular mechanism were also elucidated when cell motility was suppressed using western blotting. The results demonstrated that key proteins that are involved in tumor metastasis, including total-FAK, phospho-FAK (p-FAK), NF- $\kappa \mathrm{B}$ and MMP-9 were markedly suppressed upon siTCTP transfection, when compared with the siControl cells (Fig. 6A and B).

\section{Discussion}

TCTP is a highly-conserved protein implicated in elemental processes, including cell growth, tumorigenesis, apoptosis, activation of pluripotent cells, and cell cycle regulation. Numerous studies have identified that TCTP is highly expressed in colon cancer (12), prostate cancer (13), HCC (14) and breast cancer (22). A strong positive association between the expression levels of TCTP and the degree of metastasis was observed 
Table II. Multivariate analysis using the Cox proportion hazards regression model for the evaluation of prognostic factors.

\begin{tabular}{|c|c|c|c|c|}
\hline Variable & Patient no. & Hazard ratio & $95 \%$ Confidence interval & P-value \\
\hline \multicolumn{5}{|l|}{ Age, years } \\
\hline$<57$ & 57 & 1 & $0.713-1.543$ & 0.808 \\
\hline$\geq 57$ & 62 & 1.049 & & \\
\hline \multicolumn{5}{|c|}{$\begin{array}{l}\text { Translationally controlled tumor } \\
\text { protein immunohistochemical score }\end{array}$} \\
\hline Low & 23 & 1 & $1.602-5.121$ & $0.001^{\mathrm{a}}$ \\
\hline High & 96 & 2.864 & & \\
\hline \multicolumn{5}{|l|}{ Sex } \\
\hline Male & 84 & 1 & $0.464-1.057$ & 0.090 \\
\hline Female & 35 & 0.700 & & \\
\hline \multicolumn{5}{|l|}{ Histological type } \\
\hline Non-papillary & 99 & 1 & $0.564-1.703$ & 0.942 \\
\hline Papillary & 20 & 0.980 & & \\
\hline \multicolumn{5}{|l|}{ Metastasis } \\
\hline Negative & 46 & 1 & $0.922-2.043$ & 0.119 \\
\hline Positive & 73 & 1.372 & & \\
\hline
\end{tabular}

${ }^{a} \mathrm{P}<0.05$, considered to indicate a statistically significant difference.
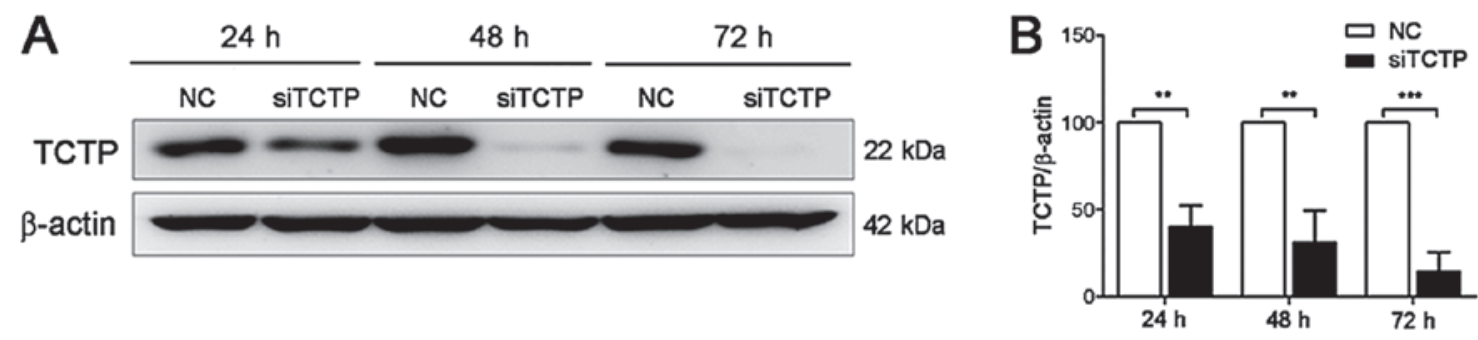

Figure 3. siTCTP effectively reduced the TCTP protein level in (A) KKU-M055 cells. Representative figures of western blotting. (B) The graph represents relative intensities. ${ }^{* *} \mathrm{P}<0.01 ;{ }^{* * *} \mathrm{P}<0.001$. NC, negative control/siControl; TCTP, translationally controlled tumor protein; si, small interfering.

in ovarian cancer (15) and colon cancer cells (16). A previous study demonstrated that high expression of TCTP was significantly associated with poorer overall survival and disease-free survival, and that TCTP also diminished the survival rate following treatment with radiotherapy and chemotherapy for patients with glioma (17).

The present study investigated the roles of TCTP in supporting the capability of CCA to progress and metastasize. The ectopic expression of TCTP was markedly detected in the cytoplasm of CCA cells, whereas no expression was observed in normal biliary cells. Additionally, high TCTP expression was associated with tumor metastasis and shorter survival time, suggesting that it may be an independent predictor of poor prognosis. These results are consistent with those observed in glioma (17) and breast cancer (22), in which TCTP was suggested to be a prognostic indicator. A previous study has demonstrated that the knockdown of TCTP suppressed tumor cell growth in prostate cancer (23). This supports the present observation of the present study that siRNA-TCTP transfection into KKU-M055 CCA cells resulted in significant growth retardation and tumorigenicity.
A previous study has revealed that TCTP is involved in metastasis, regulating tumor cell migration and invasion via the EMT process by modulating the expression of ZEB1, Twist, E-cadherin and N-cadherin (19). It was also identified that the suppression of TCTP reduced the protein levels of $\mathrm{N}$-cadherin, $\alpha$-smooth muscle actin, fibronectin and MMP-9, leading to the inhibited metastasis of mouse melanoma cells to the lungs (19). In addition, it was observed that the knockdown of TCTP inhibited proliferation, migration and invasion activities of LoVo colon adenocarcinoma cells in vitro and in vivo (16). Using CCA cells, the results of the present study revealed that TCTP expression suppression by siRNA markedly inhibited wound-induced cell migration. The inhibition of cell migration may be due to the suppression of the adhesion molecule FAK, which was reduced in its total and phosphorylated forms. The initial observations of the present study indicate that TCTP regulates the expression of FAK in CCA cells. FAK is a cytoplasmic tyrosine kinase that interacts with a receptor on the plasma membrane and with distinct protein complexes within the cell (24). Its overexpression and activation are known to promote tumor progression and metastasis (25). A 

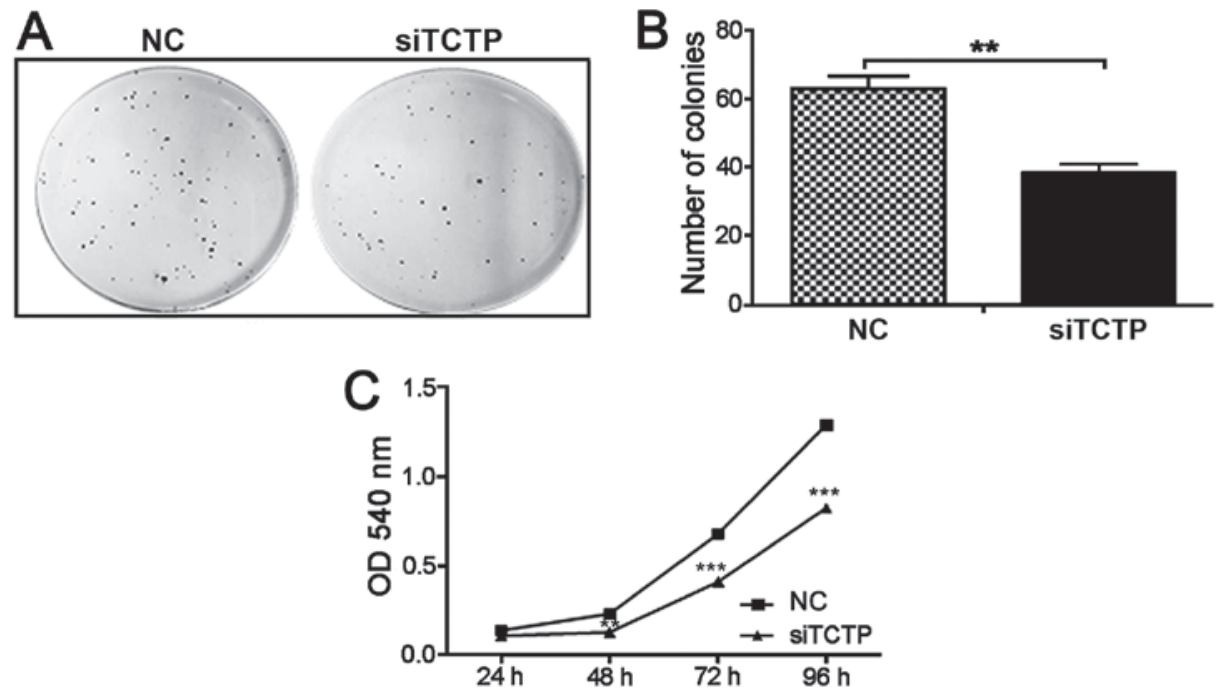

Figure 4. TCTP knockdown in KKU-M055 CCA cells (siTCTP) reduced cell proliferation. (A) Representative figures of colony formation. (B) The graph represents colony numbers as determined with a clonogenic assay. (C) Cell proliferation determined by an SRB assay at 48, 72 and $96 \mathrm{~h}$. Values are presented as the mean \pm standard deviation $\left({ }^{* *} \mathrm{P}<0.01,{ }^{* * * *} \mathrm{P}<0.001\right)$. NC, negative control/siControl; OD, optical density; SRB, sulforhodamine B colorimetric.

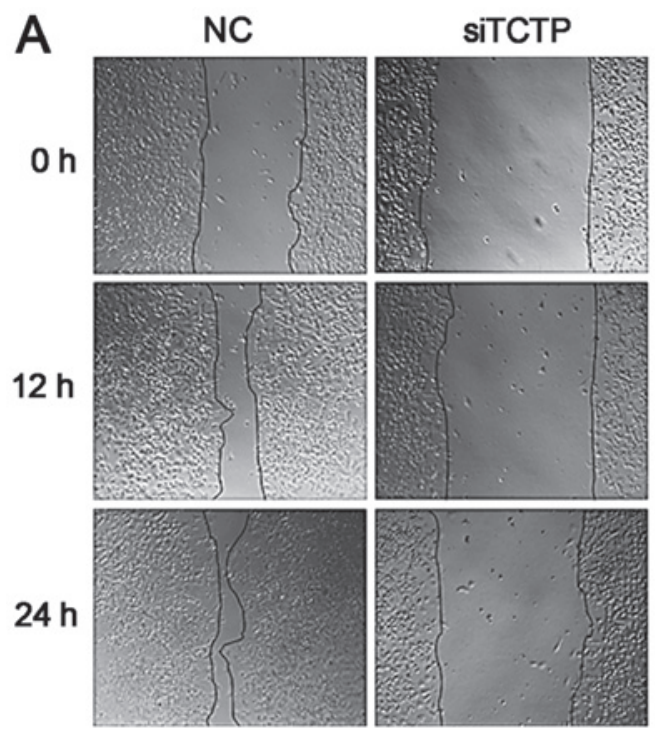

B

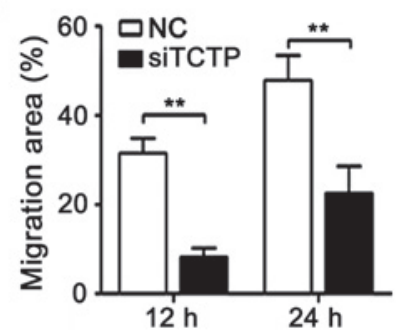

Figure 5. Suppression of TCTP attenuated the migration of (A) KKU-M055 CCA cells. The migration area (\%) observed for (B) KKU-M055 cells at 12 and $24 \mathrm{~h}$ during cell migration to close the wound. ${ }^{* *} \mathrm{P}<0.01$. TCTP, translationally controlled tumor protein; si, small interfering; CCA, cholangiocarcinoma; NC, negative control/siControl.
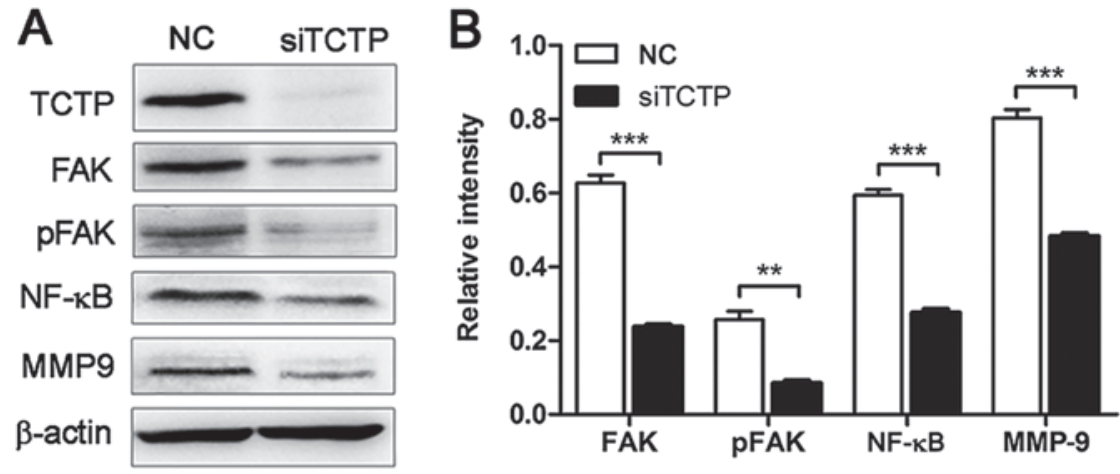

Figure 6. Transfection of siTCTP into KKU-M055 cells significantly affected the intracellular protein levels of TCTP, FAK, p-FAK, NF-kB and MMP-9, when compared with the siControl cells. (A) Representative figures of western blotting. (B) Graph representing the relative intensities. ${ }^{* *} \mathrm{P}<0.01,{ }^{* * * *} \mathrm{P}<0.001$. TCTP, translationally controlled tumor protein; si, small interfering; CCA, cholangiocarcinoma; FAK, focal adhesion kinase; p-FAK, phospho-FAK; NF- $\mathrm{B}$, nuclear factor $\kappa$-light-chain-enhancer of activated B cells; MMP, matrix metalloproteinase; NC, negative control/siControl. 
prior study revealed that TCTP and FAK were co-expressed when transformed with oncogenic H-RasV12 in p38 $\alpha$-deficient mouse embryo fibroblasts (26), indicating that TCTP and FAK are simultaneously upregulated in cells. The present study is an initial demonstration that TCTP is possibly a regulator of FAK. However, the exact mechanism by which TCTP regulates FAK expression leading to CCA progression and metastasis must be elucidated. Tumor invasion involves the proteolysis of extracellular matrix by MMPs $(21,27)$. A previous study suggested that the expression of MMP-9 is regulated by the NF-kB pathway (28). Taken together, the results of the present study indicated that the knockdown of TCTP suppressed the expression of NF- $\mathrm{NB}$ and MMP-9, indicating that TCTP controls the expression of MMP-9, which is mediated by $\mathrm{FAK} / \mathrm{NF}-\kappa \mathrm{B}$ signaling pathway to facilitate CCA metastasis. It is noted that one of the limitations of our study is the use of a single cell line (KKU-M055).

In conclusion, the present study demonstrated that high TCTP levels are associated with a poor prognosis, suggesting that TCTP may serve as an independent prognostic indicator for patients with CCA. The silencing of TCTP leads to an inhibition of CCA cell growth and migration, via reducing the expression of FAK, p-FAK, NF- $\kappa$ B and MMP-9, leading to suppressed tumor progression and metastasis. This suggests that TCTP may serve as a therapeutic target for CCA therapy.

\section{Acknowledgements}

The present study was supported by the Higher Education Research Promotion and National Research University Project of Thailand, Office of the Higher Education Commission, through the Health Cluster (SHeP-GMS) of Khon Kaen University, a grant to the Faculty of Medicine (grant no. IN58118), the Research Assistantship grants (grant no. AS58101), a grant from Khon Kaen University (grant no. 2559) and a Scholarship from the Liver Fluke and Cholangiocarcinoma Research Center. The authors would like to acknowledge Professor Trevor N. Petney (Karlsruhe Institute of Technology, Karlsruhe, Germany) for editing the MS Publication Clinic KKU, Thailand.

\section{References}

1. Olnes MJ and Erlich R: A review and update on cholangiocarcinoma. Oncology 66: 167-179, 2004.

2. Khan SA, Emadossadaty S, Ladep NG, Thomas HC, Elliott P, Taylor-Robinson SD and Toledano MB: Rising trends in cholangiocarcinoma: Is the ICD classification system misleading us? J Hepatol 56: 848-854, 2012.

3. Bertuccio P, Bosetti C, Levi F, Decarli A, Negri E and La Vecchia C: A comparison of trends in mortality from primary liver cancer and intrahepatic cholangiocarcinoma in Europe. Ann Oncol 24: 1667-1674, 2013.

4. Ghouri YA, Mian I and Blechacz B: Cancer review: Cholangiocarcinoma. J Carcinog 14: 1, 2015.

5. Shin HR, Oh JK, Masuyer E, Curado MP, Bouvard V, Fang YY, Wiangnon S, Sripa B and Hong ST: Epidemiology of cholangiocarcinoma: An update focusing on risk factors. Cancer Sci 101: 579-585, 2010.

6. Sriamporn S, Pisani P, Pipitgool V, Suwanrungruang K, Kamsa-ard S and Parkin DM: Prevalence of Opisthorchis viverrini infection and incidence of cholangiocarcinoma in Khon Kaen, Northeast Thailand. Trop Med Int Health 9: 588-594, 2004.

7. BundhamcharoenK,OdtonP,Phulkerd S and Tangcharoensathien V: Burden of disease in Thailand: Changes in health gap between 1999 and 2004. BMC Public Health 11: 53, 2011
8. Jarnagin W and Winston C: Hilar cholangiocarcinoma: Diagnosis and staging. HPB (Oxford) 7: 244-251, 2005.

9. Valle JW, Wasan H, Johnson P, Jones E, Dixon L, Swindell R, Baka S, Maraveyas A, Corrie P, Falk S, et al: Gemcitabine alone or in combination with cisplatin in patients with advanced or metastatic cholangiocarcinomas or other biliary tract tumours: A multicentre randomised phase II study-The UK ABC-01 Study. Br J Cancer 101: 621-627, 2009.

10. Bommer UA and Thiele BJ: The translationally controlled tumour protein (TCTP). Int J Biochem Cell Biol 36: 379-385, 2004.

11. Susini L, Besse S, Duflaut D, Lespagnol A, Beekman C, Fiucci G, Atkinson AR, Busso D, Poussin P, Marine JC, et al: TCTP protects from apoptotic cell death by antagonizing bax function. Cell Death Differ 15: 1211-1220, 2008.

12. Chung S, Kim M, Choi W, Chung J and Lee K: Expression of translationally controlled tumor protein mRNA in human colon cancer. Cancer Lett 156: 185-190, 2000.

13. Arcuri F, Papa S, Carducci A, Romagnoli R, Liberatori S, Riparbelli MG, Sanchez JC, Tosi P and del Vecchio MT: Translationally controlled tumor protein (TCTP) in the human prostate and prostate cancer cells: Expression, distribution, and calcium binding activity. Prostate 60: 130-140, 2004.

14. Chan TH, Chen L, Liu M, Hu L, Zheng BJ, Poon VK, Huang P, Yuan YF, Huang JD, Yang J, et al: Translationally controlled tumor protein induces mitotic defects and chromosome missegregation in hepatocellular carcinoma development. Hepatology 55: 491-505, 2012.

15. Kloc M, Tejpal N, Sidhu J, Ganachari M, Flores-Villanueva P, Jennings NB, Sood AK, Kubiak JZ and Ghobrial RM: Inverse relationship between TCTP/RhoA and p53/cyclin A/actin expression in ovarian cancer cells. Folia Histochem Cytobiol 50: 358-367, 2012.

16. Ma Q, Geng Y, Xu W, Wu Y, He F, Shu W, Huang M, Du H and $\mathrm{Li} \mathrm{M}$ : The role of translationally controlled tumor protein in tumor growth and metastasis of colon adenocarcinoma cells. J Proteome Res 9: 40-49, 2010.

17. Gu X, Yao L, Ma G, Cui L, Li Y, Liang W, Zhao B and Li K: TCTP promotes glioma cell proliferation in vitro and in vivo via enhanced $\beta$-catenin/TCF-4 transcription. Neuro Oncol 16: 217-227, 2014.

18. Graidist P, Yazawa M, Tonganunt M, Nakatomi A, Lin CC, Chang JY, Phongdara A and Fujise K: Fortilin binds $\mathrm{Ca}^{2+}$ and blocks $\mathrm{Ca}^{2+}$-dependent apoptosis in vivo. Biochem J 408: 181-191, 2007.

19. Bae SY, Kim HJ, Lee KJ and Lee K: Translationally controlled tumor protein induces epithelial to mesenchymal transition and promotes cell migration, invasion and metastasis. Sci Rep 5: $8061,2015$.

20. Hsu SM and Raine L: Protein A, avidin, and biotin in immunohistochemistry. J Histochem Cytochem 29: 1349-1353, 1981.

21. Namwat N, Puetkasichonpasutha J, Loilome W, Yongvanit P, Techasen A,Puapairoj A,SripaB,TassaneeyakulW,KhuntikeoNand Wongkham S: Downregulation of reversion-inducing-cysteine-rich protein with Kazal motifs (RECK) is associated with enhanced expression of matrix metalloproteinases and cholangiocarcinoma metastases. J Gastroenterol 46: 664-675, 2011.

22. Amson R, Pece S, Lespagnol A, Vyas R, Mazzarol G, Tosoni D, Colaluca I, Viale G, Rodrigues-Ferreira S, Wynendaele J, et al: Reciprocal repression between P53 and TCTP. Nat Med 18: 91-99, 2012.

23. Gnanasekar M, Thirugnanam S, Zheng G, Chen A and Ramaswamy K: Gene silencing of translationally controlled tumor protein (TCTP) by siRNA inhibits cell growth and induces apoptosis of human prostate cancer cells. Int J Oncol 34: 1241-1246, 2009.

24. Zhao X and Guan JL: Focal adhesion kinase and its signaling pathways in cell migration and angiogenesis. Adv Drug Deliv Rev 63: 610-615, 2011.

25. Sulzmaier FJ, Jean C and Schlaepfer DD: FAK in cancer: Mechanistic findings and clinical applications. Nat Rev Cancer 14: 598-610, 2014.

26. Alfonso P, Dolado I, Swat A, Núñez A, Cuadrado A, Nebreda AR and Casal JI: Proteomic analysis of p38alpha mitogen-activated protein kinase-regulated changes in membrane fractions of RAS-transformed fibroblasts. Proteomics 6 (Suppl 1): S262-S271, 2006.

27. Murphy G and Nagase H: Progress in matrix metalloproteinase research. Mol Aspects Med 29: 290-308, 2008.

28. Li YF, Xu XB, Chen XH, Wei G, He B and Wang JD: The nuclear factor- $\kappa \mathrm{B}$ pathway is involved in matrix metalloproteinase- 9 expression in RU486-induced endometrium breakdown in mice. Hum Reprod 27: 2096-2106, 2012. 